\title{
Journal of Diseases
}

2014. Vol.1, No.2, pp.6-12

$\operatorname{ISSN}(e): 2410-6550$

$\operatorname{ISSN}(p): 2413-838 \mathrm{X}$

DOI: 10.18488/journal.99/2014.1.2/99.1.6.12

(C) 2014 Conscientia Beam. All Rights Reserved.

(1) crossark

\section{EFFECT OF DIFFERENT CHRONOTYPE ON COMORBIDITY AND RESISTANCE TO PSYCHO-EMOTIONAL STRESS IN HYPERTENSION ASSOCIATED WITH HEPATO-BILIARY PATHOLOGY IN THE NORTH}

\author{
Sevostyanova $\mathrm{EV}^{1 \uparrow} \uparrow$--- Hasnulin $\mathrm{VI}^{2}$ \\ ${ }_{1,2}^{12}$ Scientific Center of Clinical and Experimental Medicine", Siberian Branch of RAS, (Novosibirsk, Timakov's str., 2), Russia
}

\begin{abstract}
Study of the alien inhabitants of the North - hypertensive patients with concomitant pathology of the hepato-biliary system, depending on morning or evening chronotype showed greater severity of comorbidity of hypertension and pathology of the hepato-biliary system in patients with morning chronotype. Psychophysiological analysis revealed higher level of psycho-emotional stress accompanied by violation of psychophysiological functions, important in disturbances of adaptation to natural factors and the increase in the degree of desynchronosis in patients with morning chronotype. The greater resistance to psychoemotional stress in patients living in the North of evening chronotype was revealed.
\end{abstract}

Keywords: North, Chronotype, Psycho-emotional stress, Desynchronosis, Comorbidity, Hypertension

\section{INTRODUCTION}

Recent scientific research data in the North allowed to determine that the development of chronic disease, the high incidence of morbidity and mortality, premature aging, reduction of life duration in non-indigenous population of the North are due to violation of the processes of adaptation to extreme environmental (climate, meteorological and geophysical) factors, to the development of the northern ecologically associated stress [1].

The most important natural factor that affects the human organism in the North is an unusual light regime associated with the change of the light day, the presence of polar day and polar night [2]. The light regime has a specific effect on the circadian system of an organism, being its external synchronizer.

The most important factor in the process of adaptation to environmental factors is the temporal organization of physiological functions underlying the formation of biological rhythms 
[3] and the corresponding organism's belonging to this or that chronotype: morning or evening chronotype.

The most important component of the northern stress and the risk of hypertension and comorbidity in the North is a syndrome of psycho-emotional stress [4].

Taking in account the increase in ecologically and socially conditioned psycho-emotional stress recently, the study of human resistance to stress depending on belonging to a particular chronotype acquires special significance.

The purpose of the study was to determine the resistance to climatic and geographically conditioned psycho-emotional stress on an example of hypertension combined with the pathology of the hepato-biliary system in the North in dependence on belonging to morning or evening chronotype.

\section{MATERIAL AND METHODS}

A random sample of 95 non-indigenous inhabitants of the Russian North, patients with hypertension I-II stages, combined with the pathology of the hepato-biliary system (33 men; 62 women) was examined. The age of the patients was in the range of $20-65$ years with a mean age $44.2 \pm 1.1$ years.

The study was performed according to the ethical standards laid down in the Williams [5] and has been approved by the appropriate ethics committee.

Common clinical, functional and laboratory diagnostic methods were used. All detected in the survey process diagnoses were determined and recorded in accordance with International Classification of Diseases, 10th revision (ICD-10).

Hypertension belonged to classes 110-115 ICD-10 and pathology of the hepato-biliary system - to K76 (fatty degeneration of the liver), K81 (cholecystitis), K82 (other diseases of gallbladder) and K83 (other diseases of the biliary tract).

Comorbidity and the state of functional systems (0-4 points) were estimated according to the generally accepted method of comorbidity measurement - CIRS system - Cumulative Illness Rating Scale [6].

Chronotype was determined by International Ostberg questionnaire (Ostberg test in modification by Stepanova [7].

Psycho-emotional stress and other psychophysiological and biorythmic characteristics were estimated according to the level of psycho-physiological tension and other psycho-physiological characteristics using computer program "SCREENMED" (SCCEEM SB RAMS, state registration № 970035 from 29.01.1997). The modified 8-Luscher color test, corrective test using Anfimov`s table, analysis of duration and variability of latent periods of simple sensorimotor reactions; test to determine the accuracy of subjective perception and reproduction of time intervals (test of individual minute) were performed. 
The level of pathological meteosensitivity was evaluated by the questionnaire method using a special questionnaire included in the computer system "SCREENMED".

Statistical data processing was performed using standard statistical software package STATISTICA (StatSoft), USA, version 7.0. Quantitative data are presented as mean (M) and standard error of the mean $(\mathrm{m})$ for a normal distribution of values. Statistical significance of differences was determined by paired Student's t- test for independent samples.

When the distribution did not meet the criteria of normality nonparametric U-MannWhitney test was used.

Correlation analysis was performed by Pearson method at a normal distribution and by nonparametric Spearmen criteria, when a normal distribution was not observed.

The threshold level of statistical significance was accepted at the value of criteria $p<0.05$.

\section{RESULTS}

To solve the main objectives of the study, patients were divided in two matched by age and sex groups according to belonging to a particular type of biorhythmic organization: morning chronotype ("larks") ( $\mathrm{n}=50)$ and evening chronotype ("owls") ( $\mathrm{n}=46)$.

An assessment of the state of the cardiovascular and the hepato-biliary systems, overall severity of comorbidity, as well as the assessment of central hemodynamics in the groups were performed.

An increase in the severity of hypertension and hepato-biliary pathology in patients belonging to morning chronotype ("larks") has been revealed (Table 1).

Table-1. Indicators of comorbidity (estimation by CIRS system) and hemodynamic in the patients with hypertension of morning and evening chronotypes

\begin{tabular}{l|c|c|c}
\hline & $\begin{array}{c}\text { Morning } \\
\text { chronotype (“larks”) } \\
(\mathbf{n = 5 0 )}\end{array}$ & $\begin{array}{c}\text { Evening chronotype } \\
\text { (“owls”) (n=45) }\end{array}$ & P \\
\hline Age, years & $45.82 \pm 1.34$ & $45.61 \pm 3.02$ & \\
\hline $\begin{array}{l}\text { The state of the cardio-vascular } \\
\text { system, points }\end{array}$ & $3.44 \pm 0.07$ & $3.19 \pm 0.05$ & $<0.05$ \\
\hline Systolic blood pressure, mm Hg & $159.40 \pm 3.16$ & $155.25 \pm 2.97$ & \\
\hline Diastolic blood pressure, mm Hg & $102.33 \pm 2.12$ & $95.00 \pm 1.68$ & $<0.05$ \\
\hline $\begin{array}{l}\text { The state of the hepato-biliary } \\
\text { system }\end{array}$ & $1.96 \pm 0.09$ & $1.51 \pm 0.13$ & $<0.01$ \\
\hline Comorbidity, points & $22.46 \pm 1.62$ & $20.87 \pm 1.41$ & \\
\hline
\end{tabular}

Analysis of psycho-physiological indicators in selected groups showed higher level of emotional stress in the individuals belonging to morning chronotype ("larks") (Table 2).

Psycho-emotional stress in "larks" integrated the increase in the index of psycho-emotional tension and the increase in manifestation of negative emotions (levels of anxiety, fear, mental discomfort, aggression). 
Growth of psycho-emotional stress in the patients of morning chronotype was also accompanied by a violation of a number of psycho-physiological functions: reduction of sensorimotor reactivity, enhancement of inhibitory processes in the central nervous system, decrease in productivity of attention, decrease in functional possibilities of the brain hemispheres, mainly, the right hemisphere in the processing of information (Table 2).

Table-2. Psychophysiological indices in the residents of the North - patients with hypertension combined with hepatobiliary pathology of morning and evening chronotype

\begin{tabular}{l|c|c|c}
\hline & $\begin{array}{c}\text { Morning } \\
\text { chronotype } \\
\text { «larks») }(\mathbf{n = 5 0})\end{array}$ & $\begin{array}{c}\text { Evening } \\
\text { chronotype } \\
\text { («owls») (n=45) }\end{array}$ & P \\
\hline Psycho-emotional tension, c.u & $13.33 \pm 1.83$ & $8.93 \pm 1.03$ & $<0.05$ \\
\hline $\begin{array}{l}\text { Latent period of simple sensorimotor } \\
\text { reaction, ms }\end{array}$ & $229.66 \pm 5.90$ & $203.75 \pm 5.42$ & $<0.01$ \\
\hline Inhibition of nervous processes, point & $1.54 \pm 0.02$ & $1.26 \pm 0.02$ & $<0.001$ \\
\hline Corrective test, point & $8.63 \pm 0.44$ & $10.29 \pm 0.47$ & $<0.05$ \\
\hline Anxiety, point & $0.26 \pm 0.07$ & $0.06 \pm 0.04$ & $<0.05$ \\
\hline Fear, point & $1.4 \pm 0.02$ & $0.82 \pm 0.02$ & $<0.001$ \\
\hline Psychical discomfort, point & $1.00 \pm 0.02$ & $0.55 \pm 0.01$ & $<0.001$ \\
\hline Aggressiveness, point & $1.40 \pm 0.02$ & $0.25 \pm 0.01$ & $<0.001$ \\
\hline
\end{tabular}

It is known that psycho-emotional stress is often accompanied by disturbances of the rhythms of sleep and wakefulness. Previous studies showed that desynchronosis is a characteristic constituent of the Northern stress. Taking into account the role of desynchronosis in the development of diseases it is important to explore the integral parameters describing the severity of chronobiological disorders (desynchronosis) in the surveyed persons belonging to morning and evening chronotype.

Analysis of biorhythmic characteristics in the selected groups showed that the patients belonging to morning chronotype have a higher degree of desynchronosis compared with the patients of evening chronotype (Table 3).

The patients with evening chronotype have a more favorable with regard to adaptation to changes in environmental factors biorhythmic profile with a higher synchronization of endogenous and exogenous rhythms, low index of desynchronosis and the "internal"time more close to real time. 
Table-3. Biorhythmic and adaptive indices in the residents of the North - patients with hypertension combined with hepato-biliary pathology of morning and evening chronotypes

\begin{tabular}{l|c|c|c}
\hline & $\begin{array}{c}\text { Morning } \\
\text { chronotype } \\
(« \text { larks») }(\mathbf{n = 5 0})\end{array}$ & $\begin{array}{c}\text { Evening } \\
\text { chronotype } \\
(\ll \mathbf{o w l s » )}(\mathbf{n = 4 5})\end{array}$ & P \\
\hline Individual minute, s of rhythms, & $39.96 \pm 2.46$ & $45.6 \pm 3.0$ & \\
\hline $\begin{array}{l}\text { Synchronization } \\
\text { point }\end{array}$ & $3.92 \pm 0.53$ & $5.46 \pm 0.56$ & $<0.05$ \\
\hline Desynchronosis, point & $2.54 \pm 0.23$ & $4.54 \pm 0.56$ & $<0.05$ \\
\hline $\begin{array}{l}\text { Pathological meteosensitivity, } \\
\text { point }\end{array}$ & $2.66 \pm 0.14$ & \\
\hline
\end{tabular}

One of the important integral indicators of the reduction of adaptive capacities of an organism and one of the factors influencing on development of hypertension in the North is pathological meteosensitivity [4].

The correlation analysis shows the relationship of severity of comorbidity with the level of pathological meteosensitivity.

Statistically significant direct associations of the level of pathological meteosensitivity with the degree of comorbidity $(\mathrm{r}=0.29, \mathrm{p}<0.05)$; with the severity of hypertension $(\mathrm{r}=0.32, \mathrm{p}<0.05)$; with the severity of pathology of the hepato-biliary system $(r=0.25, p<0.05)$ were revealed.

The association of pathological meteosensitivity with comorbidity was stronger in the "larks" $(\mathrm{r}=0.41, \mathrm{p}<0.05)$, than in the "owls" $(\mathrm{r}=0.15)$. Also the "larks" have stronger association of pathological meteosensitivity with the severity of hypertension $(\mathrm{r}=0.45, \mathrm{p}<0.05)$ and with the pathology of the hepato-biliary system $(\mathrm{r}=0.29, \mathrm{p}<0.05)$, as compared with the "owls" ( $\mathrm{r}=0.11$ and $\mathrm{r}=0.16$, respectively).

\section{DISCUSSION}

The greatest severity of hypertension and hepato-biliary pathology in the North was found in patients with morning chronotype.

Psycho-physiological analysis suggests that this may be due to a more pronounced decrease in adaptive resistance to emotional stress in patients of the North with morning chronotype.

Most published studies indicate to increase in the number of emotional disorders, including aggression and depression in individuals belonging to evening chronotype [8].

However these studies indicate to the connection of emotional disorders not only with chronotype but with insufficient quantity and quality of sleep.

There are some studies in which association between the number of emotional disorders and impaired sleep quality and duration, and not with evening chronotype was shown [9].

In this connection, in the evaluation of resistance to psycho-emotional stress it is necessary to separate impact of chronotype and influence of disturbances in duration and quality of sleep. 
Moreover it seems to be fundamentally important that the majority of published studies were conducted mainly on healthy people in the middle and southern latitudes.

Taking into account the peculiarities of the light regime and other geophysical factors in the North, it is justified to assume the existence of differences in the level of psycho-emotional stress and severity of negative emotional expressions in hypertensive patients of different chronotype living in middle and high latitudes.

The present study demonstrated that elevated level of psycho-emotional stress in patients of the North with morning chronotype is accompanied by the development of desynchronosis.

Desynchronosis leads to disruption of appropriate adjustment of functioning of the organs and systems to changing environmental conditions.

Reduced adaptive stability to psycho-emotional stress associated with desynchronosis may be an important factor contributing to the progression of comorbidity of hypertension and hepatobiliary pathology in the North.

Our data suggest that the persons with morning chronotype ("larks") are more likely to develop hypertension and pathology of the hepato-biliary system due to the increased psychoemotional stress and desynchronoses as compared with the persons belonging to evening chronotype ("owls").

The data obtained allow us to make the assumption that persons with evening chronotype ("owls") living in the North have a greater adaptive resistance to extreme climatic and meteorological factors, associated with a higher level of synchronization of endogenous and exogenous rhythms in these individuals.

In the literature there is evidence of an increased frequency of identifying persons with evening chronotype among residents of high latitudes [10]

May be, the increase in the incidence of persons with evening chronotype in high latitudes indicates that the extreme conditions of the North accumulate those with more persistent adaptive evening chronotype.

This is proved by the obtained in some studies data on the increased occurrence of persons with evening chronotype among the indigenous peoples of the North as compared with nonindigenous residents [11].

May be, natural selection in the North of people with evening chronotype under conditions of unusual photoperiodism, characterized by a lack of natural light in the autumn-winter period and the lack of dark time in the summer period, becomes the cause of the concentration in the North of persons with more resistant to psycho-emotional stress and the formation of comorbidity adaptive abilities.Along with this, it is important to ensure sufficient quantity and quality of sleep, which requires additional social activities to daily organization of labor and rest in the North.

These peculiarities of human resistance to environmentally induced stress in the North in dependence on chrono-phenotype require further research, revealing the functioning of adaptive 
mechanisms, as well as mechanisms of development of comorbidity in people with morning and evening chronotype.

\section{CONCLUSION}

Belonging to morning chronotype at hypertension, combined with hepato-biliary pathology in the North may be a factor that contributes to a lower adaptive resistance to psycho-emotional stress, desynchronosis and development of pathology.

\section{REFERENCES}

[1] V. Hasnulin and P. Hasnulin, "Modern views on the mechanisms of formation of the Northern stress in a man in high latitudes," Human Ecology, vol. 1, pp. 3-1 1, 2012.

[2] I. Vinogradova and V. Anisimov, Light regime of the North and age pathology. Petrozavodsk: Petro Press, 2012.

[3] K. Vaze and K. Sharma, "On the adaptive significance of circadian clocks for their owners," Chronobiology International, vol. 30, pp. 413-433, 2013.

[4] V. Hasnulin, A. Hasnulina, and E. Sevostyanova, Northern cardiometeopathies. Novosibirsk: Creative Union South-West, 2004 .

[5] J. Williams, "The declaration of Helsinki and public health," Bulletin of the World Health Organization, vol. 86, pp. 650-651, 2008.

[6] V. De Groot, H. Beckerman, and G. Lankhorst, "How to measure comorbidity: A critical review of available methods," J. Clin Epidemiol., vol. 56, pp. 22 1-229, 2003.

[7] S. Stepanova, Biorhythmic aspects of adaptation problem. Moscow: Science, 1986.

[8] A. Schlarb, R. Sopp, D. Ambiel, and J. Grünwald, "Chronotype-related differences in childhood and adolescent aggression and antisocial behavior--a review of the literature," Chronobiology International, vol. 31, pp. 1-16, 2014.

[9] R. Tavernier and T. Willoughby, "Are all evening-types doomed? Latent class analyses of perceived morningness-eveningness, sleep and psychosocial functioning among emerging adults," Chronobiology International, vol. 31, pp. 232-242, 2014.

[10] M. Borisenkov, "Human chronotype in the North," Human Physiology, vol. 36, pp. 117-122, 2010.

[11] T. Molchanova and O. Ragozina, "The incidence of discrete constitutional types in genetically notconnected populations, living in the Northern region," Russian Medical and Biological Vestnik Name Academician IP Pavlov, vol. 1, pp. 18-25, 2009. 